\title{
Fast cooling of (non)-nucleated virgin and recycled poly(propylenes) : effect of processing conditions on structural and mechanical properties
}

\author{
Citation for published version (APA): \\ Luijsterburg, B. J., Kort, de, G. W., Drongelen, van, M., Govaert, L. E., \& Goossens, J. G. P. (2015). Fast cooling \\ of (non)-nucleated virgin and recycled poly(propylenes) : effect of processing conditions on structural and \\ mechanical properties. Thermochimica Acta, 603, 94-102. https://doi.org/10.1016/j.tca.2014.09.025
}

DOI:

10.1016/j.tca.2014.09.025

Document status and date:

Published: 01/01/2015

\section{Document Version:}

Publisher's PDF, also known as Version of Record (includes final page, issue and volume numbers)

\section{Please check the document version of this publication:}

- A submitted manuscript is the version of the article upon submission and before peer-review. There can be important differences between the submitted version and the official published version of record. People interested in the research are advised to contact the author for the final version of the publication, or visit the DOI to the publisher's website.

- The final author version and the galley proof are versions of the publication after peer review.

- The final published version features the final layout of the paper including the volume, issue and page numbers.

Link to publication

\footnotetext{
General rights

- You may freely distribute the URL identifying the publication in the public portal. follow below link for the End User Agreement:

www.tue.nl/taverne

\section{Take down policy}

If you believe that this document breaches copyright please contact us at:

openaccess@tue.nl

providing details and we will investigate your claim.
}

Copyright and moral rights for the publications made accessible in the public portal are retained by the authors and/or other copyright owners and it is a condition of accessing publications that users recognise and abide by the legal requirements associated with these rights.

- Users may download and print one copy of any publication from the public portal for the purpose of private study or research.

- You may not further distribute the material or use it for any profit-making activity or commercial gain

If the publication is distributed under the terms of Article 25fa of the Dutch Copyright Act, indicated by the "Taverne" license above, please 


\title{
Fast cooling of (non)-nucleated virgin and recycled poly(propylenes): Effect of processing conditions on structural and mechanical properties
}

\author{
B.J. Luijsterburg ${ }^{\mathrm{a}, \mathrm{b}}$, G.W. de Kort $^{\mathrm{a}}$, M. van Drongelen ${ }^{\mathrm{c}}$, L.E. Govaert ${ }^{\mathrm{c}}$, J.G.P. Goossens ${ }^{\mathrm{a}, *}$ \\ a Laboratory of Polymer Materials, Department of Chemical Engineering and Chemistry, Eindhoven University of Technology, P.0. Box 513, 5600 MB \\ Eindhoven, The Netherlands \\ ${ }^{\mathrm{b}}$ Top Institute Food and Nutrition, P.O. Box 557, 6700 AN Wageningen, The Netherlands \\ c Polymer Technology, Department of Mechanical Engineering, Eindhoven University of Technology, P.O. Box 513, 5600 MB Eindhoven, The Netherlands
}

\section{A R T I C L E I N F O}

\section{Article history:}

Available online 23 October 2014

\section{Keywords:}

Fast scanning calorimetry

Dilatometry

Isotactic poly(propylene)

Mechanical recycling

Nucleating agents

Mechanical properties

Polymer processing

Structure-property relationships

Polymorphism

\begin{abstract}
A B S T R A C T
In this study, the effect of processing parameters, i.e., the cooling rate and pressure, on the structureproperty relationships for nucleated and non-nucleated $i$-PP from virgin and recycled sources was investigated. Special attention was given to the brittle-to-ductile transition of nucleated $i$-PP from plastic packaging waste. Differential fast scanning calorimetry and dilatometry were used to mimic industrial process conditions. From the calorimetric experiments, it was observed that under ambient pressure the mesomorphic phase was formed upon fast cooling, which was confirmed by WAXD analysis. The dilatometry results showed that by applying pressure also $\gamma$-phase crystals are formed. Nucleated samples showed an increased tendency for the $\gamma$-phase formation and a decreased tendency for mesomorphic phase formation. Up to now, recycled $i$-PP showed a brittle behavior, but this study showed that by applying a sufficiently high cooling rate, the yield stress can be reduced and a stabilization of the deformation can be obtained leading to a ductile behavior for recycled $i$-PP.
\end{abstract}

(c) 2014 Elsevier B.V. All rights reserved.

\section{Introduction}

Plastics are used in a wide variety of applications, including packaging products. After a short service life, the product is mostly disposed. Recycling of these plastics has gained a lot of attention in recent years. Mechanical recycling of waste plastics is considered the preferred option from the environmental point of view [1]. Commingled plastics from e.g. household waste are sorted with near-infrared-technology and are further cleaned. Despite improved sorting efficiencies, some polymeric contaminations are always present in post-consumer waste, which reduce the mechanical properties significantly. It was shown that a sorted polymer waste stream typically contains $5-10 \%$ contamination of another polymer [2].

One of the sorted polymer waste streams is poly(propylene) (PP). PP is a versatile polymer which is suitable for many applications because of its relatively high stiffness, tensile and impact strength. Isotactic PP ( $i$-PP) is the most common form of PP. It is known that $i$-PP degrades by chain scission when reprocessing the material [3]. For sorted $i$-PP waste, contamination in

\footnotetext{
* Corresponding author. Tel.: +31 402473899.

E-mail address: j.g.p.goossens@tue.nl (J.G.P. Goossens).
}

combination with degradation during lifetime leads to undesired brittle failure. Mechanical recycling of plastic waste can only be successful if the material can be used in existing processing techniques and at sufficient scale.

$i$-PP is a polymer which can partially crystallize upon cooling from the melt. It can crystallize in different crystal structures, depending on the processing conditions. All crystal structures have a three-fold helical conformation of the polymer chains, but differ in the packing density. The $3{ }_{1}$-helix has three monomers per turn and can be either right or left handed. A further distinction can be made based on the orientation of the methyl group with respect to the chain axis, which can be either up or down. The $\alpha$-crystal phase is the thermodynamically most stable phase. The $\alpha$-crystal phase has a monoclinic unit cell $(a=6.65 \AA ̊, b=20.96 \AA, c=6.5 \AA)$. A peculiar feature of the $\alpha$-crystal phase is lamellar branching, also known as cross-hatching: one type of lamellae (parent lamellae) forms a nucleation site for daughter lamellae that grow under a specific angle. For $i$-PP, this angle between parent and daughter lamellae is $80^{\circ}[4,5]$. Despite the presence of contaminations, $i$-PP from waste materials normally crystallizes in the $\alpha$-crystal phase, which was investigated by differential scanning calorimetry (DSC) and wide-angle X-ray diffraction (WAXD) [6].

The $\beta$-crystal phase in $i$-PP is only formed when specific nucleating agents, such as $\gamma$-quinacridone, are added to the 
polymer or under special crystallization conditions, e.g. crystallization under temperature gradients or from an oriented melt $[7,8]$. It was first observed by Padden and Keith in 1959 [9]. The $\beta$-crystal phase has a trigonal unit cell $(a=b=11.01 \AA$ and $c=6.5 \AA)$ containing three isochiral helices. The lamellae in the $\beta$-crystal phase are not cross-hatched but parallel, thereby providing greater chain mobility within the lamellae under load [10]. The $\beta$-crystal phase is a metastable phase and recrystallizes to the $\alpha$-crystal phase when heated above $145^{\circ} \mathrm{C}$, a process which is known as the $\beta-\alpha$ transformation [11-13].

The $\gamma$-crystal phase is formed when crystallization takes place under high pressures and moderate cooling rates. This crystal phase is typically formed more easily in lower molecular weight polymers [14-16] or in the presence of an $\alpha$-olefin comonomer [17]. The $\gamma$-crystal phase has an orthorhombic unit cell $(a=8.54 \AA$, $b=9.93 \AA$, $c=42.4 \AA$ ) containing layers of non-parallel organized chain segments. Lamellae of the $\gamma$-crystal phase generally nucleate on the $\alpha$-lamellae by an epitaxial mechanism that is comparable with the cross-hatched structure within the $\alpha$-crystal phase, but under an angle of $40^{\circ}[1,5]$.

The mesomorphic phase is formed when $i$-PP is quenched to $0-$ $40^{\circ} \mathrm{C}$ from the melt at ambient or high pressures [18-20]. It consists of parallel chains with a high degree of order in the longitudinal direction (the helical structure is preserved), but no crystallographic register in the lateral packing [21-26]. The mesomorphic phase can be considered as an intermediate, frozen-in state of order in the crystallization process. Upon fast cooling the folding of polymer chains into lamellae is hindered. Its form is metastable and undergoes a transformation to the $\alpha$-crystal phase when the polymer is heated (typically between 40 and $80^{\circ} \mathrm{C}$ ).

The mechanical properties of semi-crystalline polymers are strongly dependent of their crystallinity, lamellar thickness, and type of crystal structure, which depend on the processing conditions [27]. A higher cooling rate during crystallization leads to a lower yield stress [28] and a higher strain-at-break. Lowering the yield stress of recycled $i$-PP could result in ductile instead of brittle behavior. Earlier results showed that, for the same crystallinity, the nodular mesomorphic phase was ductile with elongations-at-break up to $450 \%$, while brittle fracture was observed for a spherulitic $\alpha$-crystal phase in the same $i$-PP [29]. Another study showed that for $i$-PP's with similar crystallinities the $\alpha$-crystal phase was ductile with an elongation-at-break of $300 \%$, an elongation-at-break of over $600 \%$ for the mesomorphic phase and an elongation-at-break of over $1000 \%$ for the $\gamma$-crystal phase, which was explained in terms of a phase transition from the $\gamma$-crystal phase to the mesomorphic phase during deformation [30]. A study on the effect of stereoregularity of $i$-PP on the crystal phase formation showed that the mechanical properties of $i$-PP can be tuned using metallocene catalysts [31]. The mesomorphic phase formation was favored for stereodefective $i$-PP. The cooling conditions were found to predetermine the morphology and shape of crystals, lamellae or nodules, while annealing offers additional options to modify the mechanical properties through the lamellar thickness, perfection, and crystallinity for slowly cooled samples. Annealing of quenched samples permits a precise adjustment of crystallinity and size of the nodular crystals without affecting the external habit of the crystals. Here, the modulus and tensile strength can be tailored while maintaining the ductility of the mesomorphic phase [32,33].

These mechanical properties are often measured in tensile testing. The yield stress $\sigma_{y}$, i.e., the first maximum in the stressstrain curve, indicates the transition between elastic deformation at small deformations, described by Hooke's law, and plastic deformation. Plastic deformation usually starts by the formation of a neck, initiated by lamellar slip due to local stress concentration. After the formation of a stable neck, the neck propagates throughout the sample. The draw ratio of the material in the stable neck is better known as the 'natural draw ratio' or $\lambda_{n}$. After this draw ratio, a material can show strain hardening. This process is mainly governed by the increase in stress due to deformation applied on the entanglements in the amorphous phase. The slope of this regime is called the strain hardening modulus $G_{R}$. A higher entanglement density results in an increase in strain hardening modulus. The relationship between yield stress $\sigma_{y}$, estimated draw ratio in the neck $\lambda_{n}$, and strain hardening modulus $G_{R}$ is well known for samples measured in compression [34,35]. In tensile deformation, the quantitative determination of strain hardening modulus is difficult, since geometrical factors have a large influence on the observed behavior after yielding of the material. However, qualitatively the following relation is valid.

$\lambda_{n} \in\left(\frac{\sigma_{y}}{G_{R}}\right)$

This relation indicates that, for similar yield stresses, an increase in natural draw ratio must be accompanied by a decrease in strain hardening modulus. Critical in the stress-strain behavior of polymers in tensile testing is the formation of a stable neck. When $\sigma_{y} / G_{R}<3$, uniform (homogeneous) deformation will be observed. If $\sigma_{y} / G_{R}>3$, necking is observed, and deformation can either be stable or unstable. When $\lambda_{n}$ increases, the stress concentrates on a relatively small cross-sectional area and the smallest defect can cause failure. At high $\lambda_{n}$ the material becomes brittle $[36,37]$. Furthermore, the neck stability is influenced by the presence of contaminants (failure by initiation).

High pressures and cooling rates favor the formation of either crystals with a small lamellar thickness, the $\gamma$-crystal phase or the mesomorphic phase for $i$-PP. All contribute to a lower yield stress. On laboratory scale, the formation of these phases can be investigated by dilatometry and differential fast scanning calorimetry $[20,28,38,39]$. This type of DSC instrument allows the use of extremely high heating and cooling rates and is ideal for the investigation of metastable structures. Samples are placed directly on a micro-electro-mechanical systems (MEMS)-based sensor using a microscope and not in crucibles as in conventional DSC. Heating and cooling rates of $1000{ }^{\circ} \mathrm{Cs}^{-1}$ can easily be obtained. It was demonstrated that a non-isothermal crystallization model can be used to accurately describe the multi-phase crystalline evolution for the $\alpha-, \beta-, \gamma$ - and mesomorphic phase [20]. The relative amounts of each crystal phase were calculated from X-ray analysis [40]. With increasing cooling rate, the $i$-PP crystal phase changed from the $\alpha$ - to the mesomorphic phase. Differential fast scanning calorimetry studies showed that this transition occurs at cooling rates between $200-500^{\circ} \mathrm{C} \mathrm{s}^{-1}$ [41]. The transition depends on the material characteristics such as molecular weight and molecular weight distribution, but an exact correlation has not yet been found [42].

When a polymer melt gets into contact with the cold wall of the mold in compression molding or injection molding, the material in close contact to the wall cools very rapidly, which can be investigated by using non-isothermal crystallization experiments in differential fast scanning calorimetry [43]. The material cools down more slowly towards the center of the polymer product. Here, a gradient in cooling rate is observed, which can be well investigated with isothermal crystallization experiments in differential fast scanning calorimetry. To obtain a full picture of the cooling conditions in compression molding or injection molding, both types of experiments have to be considered. From non-isothermal crystallization results, continuous cooling curve 
(CCC) diagrams were constructed which show characteristic bellshaped curves for most materials. However, a clear transition is seen in the CCC of $i$-PP. This transition is explained by the change in crystal structure from the $\alpha$-crystal phase to the nodular mesomorphic phase at higher undercooling in isothermal experiments or higher cooling rates in non-isothermal experiments. The addition of $\alpha$-olefin comonomer to $i$-PP resulted in a decreased ordering time for the mesomorphic phase, which decreased further by increasing bulkiness of the comonomer unit [17]. The addition of nucleating agents facilitates crystallization, leading to faster crystal formation and a shift in the CCC diagram towards faster crystallization times.

The objective of this research is to study the effect of cooling rate and pressure on the crystallization behavior of nucleated and non-nucleated $i$-PP and to use the altering of these conditions to improve the mechanical properties of $i$-PP from plastic packaging waste. To get a better understanding of the effect of different fillers present in recycled $i$-PP on the cooling rate-dependent crystal phase formation and mechanical behavior, differential fast scanning calorimetry, dilatometry, and tensile tests were performed for various $i$-PP samples. These tests give valuable information about structure-property relationships in nucleated and non-nucleated $i$-PP, as well as for more complex systems such as recycled $i$-PP. As a reference, commercially available nonnucleated and $\alpha$-phase nucleated PP grades used in the packaging industry were used. As real-life examples, recycled $i$-PP from both post-consumer and post-industrial waste were used, which contain impurities. The isothermal crystallization kinetics are related to the $i$-PP crystal structure, which is measured with WAXD. Finally, differences in processing conditions, mimicked in a home-built dilatometer which can impose realistic processing conditions, such as cooling rate and pressure, to the materials under investigation, are related to the corresponding mechanical properties in tensile mode.

\section{Experimental}

The materials used in this study were a virgin $i$-PP, a nucleated virgin $i$-PP and two recycled $i$-PPs. The non-nucleated virgin $i$-PP was supplied by Borealis, Linz, Austria (HD234CF, code PP-1) and was used in earlier studies $[20,28]$. The virgin nucleating agentcontaining grade homopolymer 578N (PP-2), was supplied by Sabic Europe, Geleen, the Netherlands. Vision PPC black 2008 (PIPP, originating from industrial waste, filtered at $250 \mu \mathrm{m}$ ) was provided by AKG, Vroomshoop, the Netherlands. Dipolen PP (German post-consumer PP, PCPP, filtered at $80 \mu \mathrm{m}$ ) was provided by MTM Plastics, Niedergebra, Germany. All materials were received and used in pellet form. The recycled $i$-PP samples contain a significant amount of poly(ethylene) (PE, 5-10\%), as determined by DSC and Fourier transform infrared spectroscopy (FT-IR) analysis [2].

To determine the molecular weight distribution, high-temperature size exclusion chromatography (HT-SEC) analysis was performed using a Polymer Laboratories PLGPC220 chromatograph equipped with four columns (four PLgel Olexis, $300 \mathrm{~mm} \times 7.5 \mathrm{~mm}$, Polymer Laboratories). Samples $\left(2 \mathrm{mg} \mathrm{mL}^{-1}\right)$ were eluted with trichlorobenzene at a flow rate of $1 \mathrm{mLmin}^{-1}$ at $160^{\circ} \mathrm{C}$. The molecular weights were calculated based on PE standards. Measurements of recycled samples were filtered before injection using a $1 \mu \mathrm{m}$ mesh size filter at $150^{\circ} \mathrm{C}$.

The materials were compression molded at $200^{\circ} \mathrm{C}$ and 100 bar for $3 \mathrm{~min}$ in a Collin Presse 300G and subsequently cooled with water. The average cooling rate is estimated to be in the order of $1{ }^{\circ} \mathrm{Cs}^{-1}$. Five tensile specimens (Type 5B, ISO 527) were cut from the compression-molded plaque for mechanical analysis.
Dilatometry was used to prepare tensile samples under elevated pressures and high cooling rates. A Pirouette pressurevolume-temperature (PVT) apparatus from IME Technologies was used in this study [44-47]. Various cooling rates could be applied by varying the coolant. Without a coolant, the initial cooling rate, determined between $190^{\circ} \mathrm{C}$ and $130^{\circ} \mathrm{C}$, was approximately $0.1^{\circ} \mathrm{C}$ $\mathrm{s}^{-1}$, with forced-air cooling or water cooling $1^{\circ} \mathrm{Cs}^{-1}$ or $90^{\circ} \mathrm{Cs}^{-1}$ can be achieved, respectively. The cooling profile in the $0.5 \mathrm{~mm}$ thick ring-shaped samples is independent of the distance of the location of interest to the cooling surface. The pressure was varied from 100 to 1200 bar. Each experiment was done in triplo, from which in total five specimens were taken for tensile testing and WAXD analysis.

Mechanical properties were measured with a Zwick Z100 tensile tester equipped with a $100 \mathrm{~N}$ load cell. The specimens were measured according to ISO 527 norms at a test speed of $10^{-3} \mathrm{~s}^{-1}$ and a gauge length of $15 \mathrm{~mm}$. A pre-load of $2 \mathrm{~N}$ was applied for dilatometer rings and $0.2 \mathrm{~N}$ for compression-molded tensile specimens.

WAXD patterns of the dilatometry rings were collected on a Rigaku Geigerflex Bragg-Brentano powder diffractometer, operating at $40 \mathrm{kV}$ and $30 \mathrm{~mA}$, using $\mathrm{CuK} \alpha$ radiation $(\lambda=1.54 \AA)$ filtered with a graphite monochromator. Scans were made with a step size of $0.02^{\circ}$ and a dwell time of $2 \mathrm{~s}$. The reflections were measured in the $2 \theta$ range from 5 to $30^{\circ}$. Baseline correction and peak deconvolution was performed with the PeakFit analysis program. The $\gamma$ - and meso-content were calculated by using the ratio between the characteristic reflection peaks for both the $\gamma-, \alpha$ - and mesomorphic phase:

$$
\gamma(\%)=\frac{A_{(117)_{\gamma}}}{A_{(117)_{\gamma}}+A_{(130)_{\alpha}}}
$$

$\mathrm{m}(\%)=\frac{A_{\text {meso1 }}}{A_{\text {meso1 }}+A_{(130)_{\alpha}}}$

where $A$ is the area under the deconvoluted peak of the crystal reflection of interest, indicated as subscript, and meso 1 is the diffraction peak of the mesomorphic phase observed in the low $2 \theta$ range.

Differential scanning calorimetry was done to calculate the crystallinity of the materials as prepared with dilatometry and compression molding. A TA Instruments DSC Q1000 and standard aluminum pans were used. Samples with a mass between 1 and $5 \mathrm{mg}$ were heated from 30 to $220^{\circ} \mathrm{C}$ at a rate of $10^{\circ} \mathrm{C} \mathrm{min}{ }^{-1}$, kept isothermal for $5 \mathrm{~min}$ and subsequently cooled down to $30^{\circ} \mathrm{C}$. The crystallinity was measured by dividing the melting enthalpy of the sample by the melting enthalpy of $100 \%$ crystalline $i$-PP $(207.1 \mathrm{~J}$ $\left.\mathrm{g}^{-1}\right)$.

Differential fast scanning calorimetry was done to simulate high cooling rates during quenching. A Mettler Toledo Flash DSC 1 STARe system equipped with a Huber Intracooler T100 was used. The sample size used is typically $100 \mathrm{ng}$. Both isothermal and non-isothermal experiments were done to give a complete overview of $i$-PP crystallization. In non-isothermal experiments, specimens were heated at $1000^{\circ} \mathrm{C} \mathrm{s}^{-1}$ to $220^{\circ} \mathrm{C}$, kept isothermal for $0.1 \mathrm{~s}$ and were then cooled down. The heat flow was measured for all materials at several cooling rates in the range of $10-5000^{\circ} \mathrm{C} \mathrm{s}^{-1}$. From the non-isothermal data, continuous cooling curve (CCC) diagrams were constructed. Here, the crystallization temperature was taken from the peak maximum or, in case of a shoulder, from the maximum derivative of the curve. The time to cool down from $195^{\circ} \mathrm{C}$ to the crystallization temperature was 
Table 1

HT-SEC analysis of $i$-PP grades.

\begin{tabular}{|c|c|c|c|c|}
\hline Material & $M_{n}\left(\mathrm{~kg} \mathrm{~mol}^{-1}\right)$ & $M_{w}\left(\mathrm{~kg} \mathrm{~mol}^{-1}\right)$ & $M_{w} / M_{n}(-)$ & $\mathrm{MFI}^{\mathrm{a}}\left(\mathrm{g} 10 \mathrm{~min}^{-1}\right)$ \\
\hline PP-1 & 59 & 194 & 3.3 & 8 \\
\hline PP-2 & 30 & 156 & 5.1 & 25 \\
\hline PIPP & 54 & 156 & 2.9 & 20 \\
\hline PCPP & 23 & 96 & 4.2 & 11 \\
\hline
\end{tabular}

a Data from product specifications.

taken as the crystallization time [43]. In isothermal experiments, specimens were heated at $1000^{\circ} \mathrm{C} \mathrm{s}^{-1}$ to $220^{\circ} \mathrm{C}$, kept isothermal for $0.1 \mathrm{~s}$ and were then cooled down at a rate of $2500^{\circ} \mathrm{C} \mathrm{s}^{-1}$ to the desired isothermal crystallization temperature (from 0 to $110^{\circ} \mathrm{C}$ in steps of $2.5^{\circ} \mathrm{C}$ ). After crystallization the samples were further cooled down to $-50^{\circ} \mathrm{C}$ at a rate of $1000^{\circ} \mathrm{C} \mathrm{s}^{-1}$. When cooling down from the melt, the time between $195^{\circ} \mathrm{C}$ (thermodynamic melting point of $i$-PP) and the maximum of the crystallization peak was taken as the crystallization time [43].

\section{Results and discussion}

First, the materials were molecularly characterized by HT-SEC Then, the effect of fillers on the critical cooling rate and crystal phase formation of $i$-PP is discussed by applying different cooling rates in a differential fast scanning calorimeter. Additionally, the effect of pressure on $i$-PP crystal phase formation is described by using dilatometry experiments and WAXD. From the dilatometer rings, tensile specimens are prepared for determination of mechanical properties, which is discussed at the end of this manuscript.

\subsection{Molecular characterization}

The molecular weights of the starting materials were determined with HT-SEC. The results are presented in Table 1 and show that the virgin $i$-PP grade from Borealis (PP-1) is of high molecular weight $\left(M_{w}\right)$. The nucleated virgin grade from Sabic (PP-2) is lower molecular weight with a broader MWD. PIPP has a molecular weight comparable to PP-2, but a much narrower MWD. The postconsumer $i$-PP (PCPP) has the lowest molecular weight, but a moderate melt flow index (MFI).

\subsection{Non-isothermal fast cooling of nucleated and non-nucleated i-PP}

Non-isothermal fast cooling experiments were performed for nucleated virgin and recycled $i$-PP to simulate cooling conditions throughout a compression-molded product. These results are given in Fig. 1. For the virgin $i$-PP grade PP-1 (Fig. 1A), one single crystallization peak is seen at low cooling rates, which corresponds to the $\alpha$-crystal phase. It is observed that the crystallization temperature decreases with increasing cooling rate and that the crystallization peak broadens. In general, the crystallization enthalpy decreases with increasing cooling rate, hence the crystallinity decreases. At cooling rates $\geq 150^{\circ} \mathrm{Cs}^{-1}$ a shoulder at lower temperatures is observed, which indicates a transition to the mesomorphic phase of $i$-PP. These results are in agreement with literature [38]. At cooling rates higher than $800^{\circ} \mathrm{Cs}^{-1}$ a fully amorphous polymer is obtained. At high cooling rates, the glass
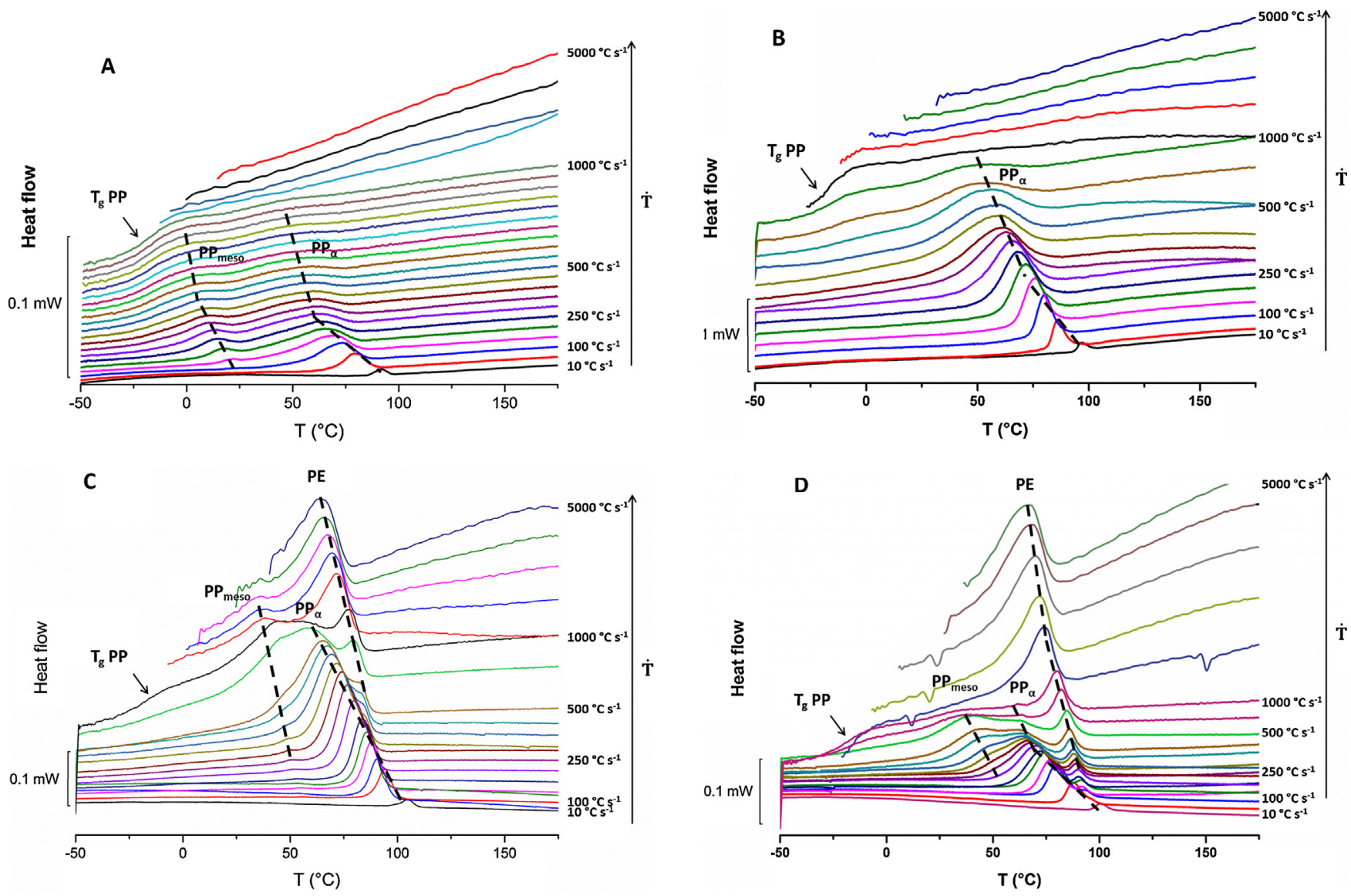

Fig. 1. Non-isothermal crystallization of PP-1 (A), PP-2 (B), PIPP (C) and PCPP (D) at various cooling rates (exo up). The dashed lines are a guide to the eye. 

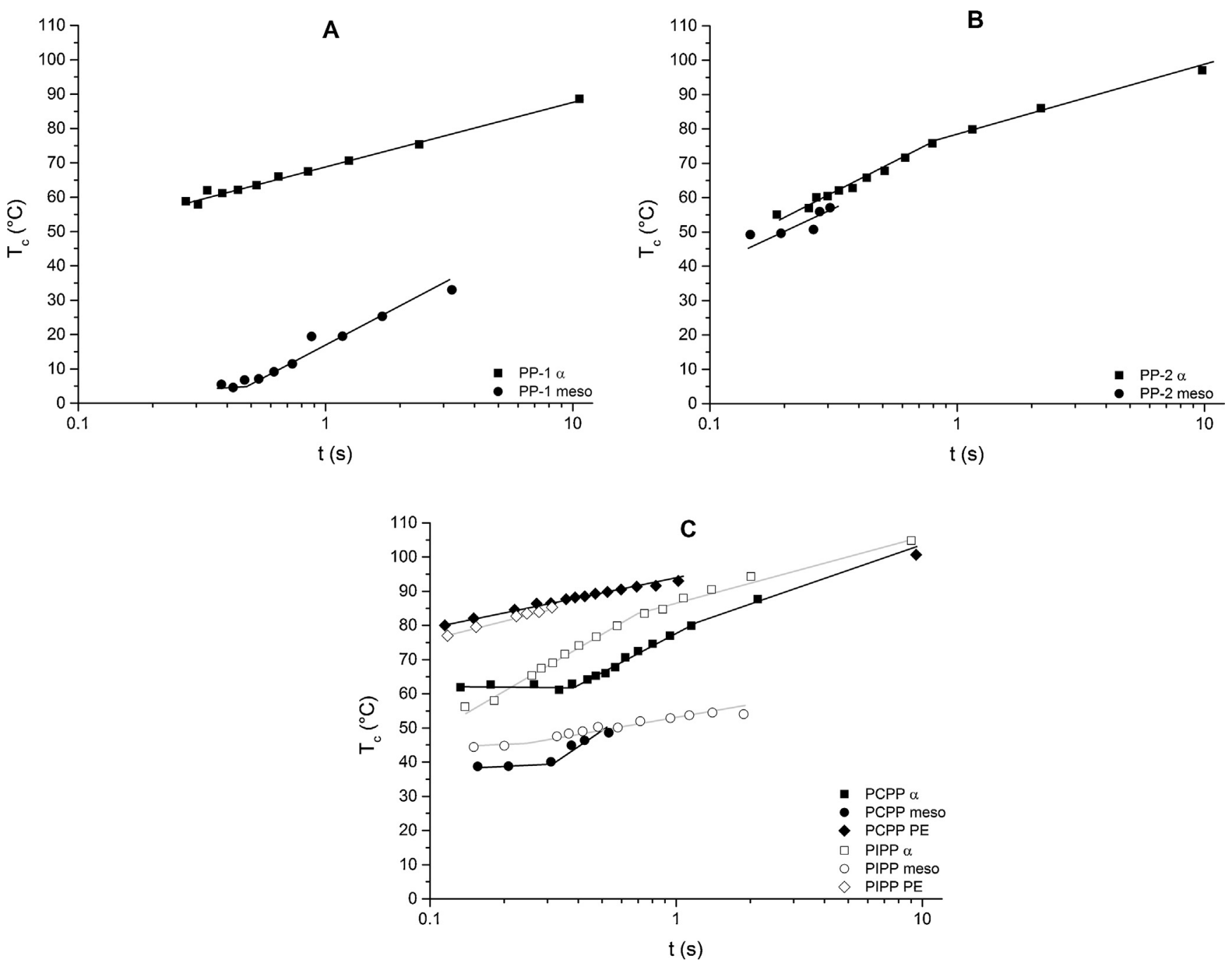

Fig. 2. Continuous cooling curve (CCC)-diagrams of non-isothermal crystallized non-nucleated virgin $i$-PP (A), nucleated virgin $i$-PP (B), and recycled $i$-PP (C).

transition temperature is visible. At very high cooling rates $\left(>1000^{\circ} \mathrm{C} \mathrm{s}^{-1}\right)$, the signal becomes unstable at lower temperatures. For this reason, only data related to stable operation is plotted. For PP-2 (Fig. 1B) similar results are obtained, with the difference that, in this case, no clear distinction between the $\alpha$-crystal phase and the mesophase is seen. Compared to de Santis et al. [38] where cooling rates of $1000^{\circ} \mathrm{Cs}^{-1}$ were also applied and a complete amorphous $i$-PP was obtained, the nucleated $i$-PP grade used in this study shows faster crystallization kinetics. At a cooling rate of $2500^{\circ} \mathrm{Cs}^{-1}$, a fully amorphous polymer is obtained. For polymers the crystallization process is governed by nucleation and growth. The crystal growth of $i$-PP under quiescent conditions is independent of molecular weight or width of the molecular weight distribution [48]. The presence of nuclei promotes polymer crystallization. Therefore, the critical cooling rate, where a fully amorphous polymer is obtained, is higher for a nucleated system (PP-2). This was also observed in literature [41]. Although the crystallization of $i$-PP can be suppressed by increasing the cooling rate, PE crystallization cannot be circumvented. Since PE crystals act as nuclei for $i$-PP $[49,50]$, crystallization of $i$-PP can even be observed at high cooling rates $\left(3000^{\circ} \mathrm{C} \mathrm{s}^{-1}\right.$ for PIPP).

Fig. $1 C$ and D shows the results of similar experiments for PIPP and PCPP, respectively. The $i$-PP crystallization peaks show a similar trend as observed for virgin $i$-PP. A similar shoulder peak develops with increasing cooling rate, but is already visible at lower cooling rates $\left(250^{\circ} \mathrm{C} \mathrm{s}^{-1}\right)$. An additional distinctive peak around $90^{\circ} \mathrm{C}$ is observed that only shifts to somewhat lower temperatures with increasing cooling rate. This peak originates from the PE phase in recycled $i$-PP. Contradictory to the results obtained for virgin $i$-PP, the recycled $i$-PP grades used in this study are not fully amorphous at high cooling rates. PE crystallizes even at cooling rates of $5000^{\circ} \mathrm{C} \mathrm{s}^{-1}$. However, these results show that even in a complex system such as PCPP similar crystal phases as in $i$-PP can be obtained as a function of cooling rate.

The crystallization time and temperature were calculated and organized in CCC diagrams, which are shown in Fig. 2. The observed trend is similar to results from literature [43]. Differences in results can be attributed to a better heat transfer in the equipment used in this research. For non-nucleated material (Fig. 2A), the $\alpha$ - and mesomorphic crystallization temperature are clearly shown. The difference in $\alpha$ - and mesomorphic crystallization temperature is significantly larger than for the nucleated system (Fig. 2B). In nucleated $i$-PP, the increase in crystallization temperature of the mesomorphic phase is more pronounced than in the $\alpha$-crystallization temperature. Fig. $2 \mathrm{C}$ displays the results obtained for continuous fast cooling of recycled $i$-PP. It can be seen that the complex systems from waste $i$-PP behave similar to virgin nucleated $i$-PP, with an additional PE crystallization peak at higher 

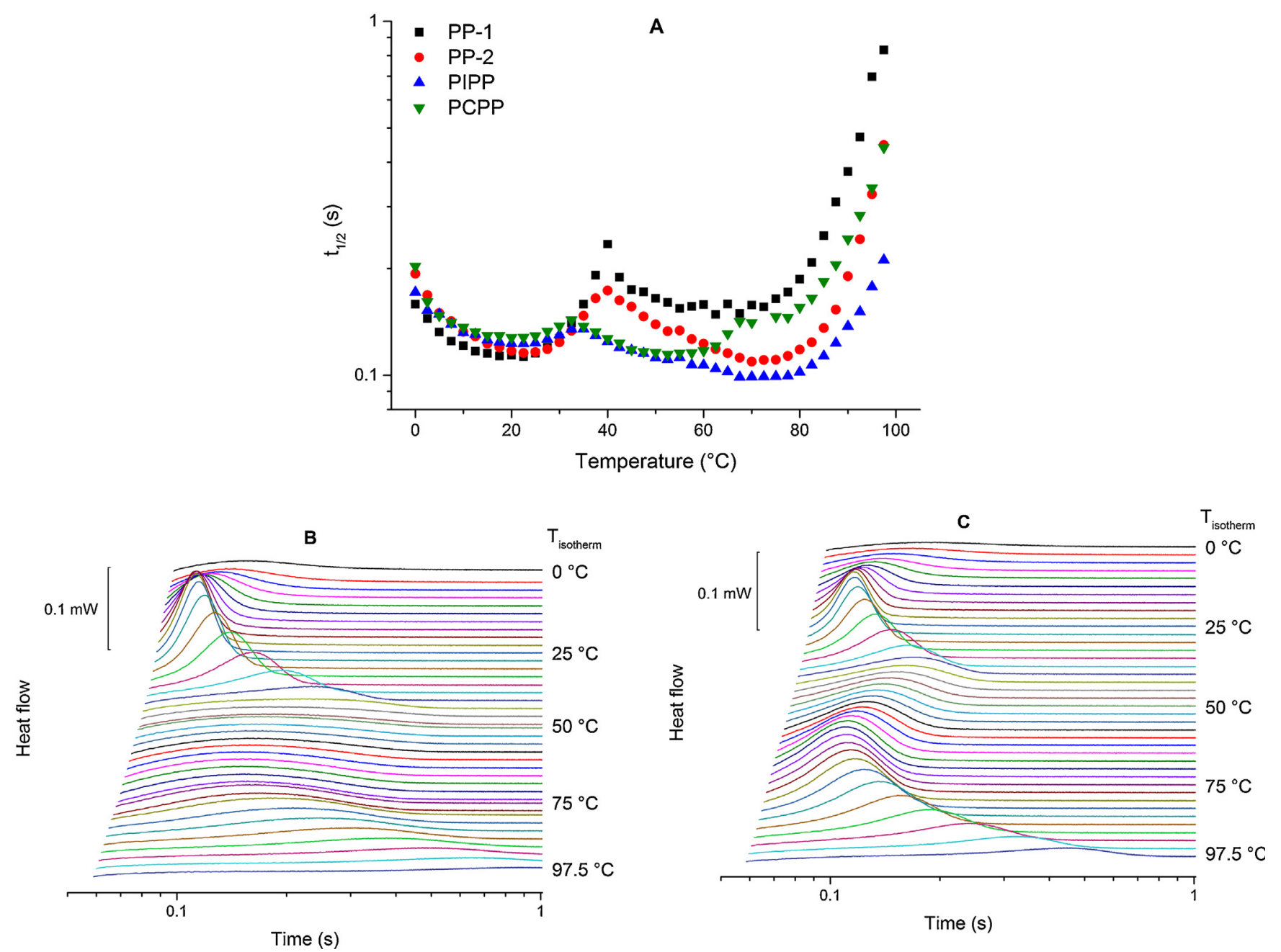

Fig. 3. Crystallization half time $t_{1 / 2}$ as a function of crystallization temperature for isothermally crystallized $i$-PP (A). The heat flow curves of PP-1 and PP-2 (exo up) at different isothermal crystallization temperatures are given in (B) resp. (C).

temperatures, which does not change significantly with cooling rate.

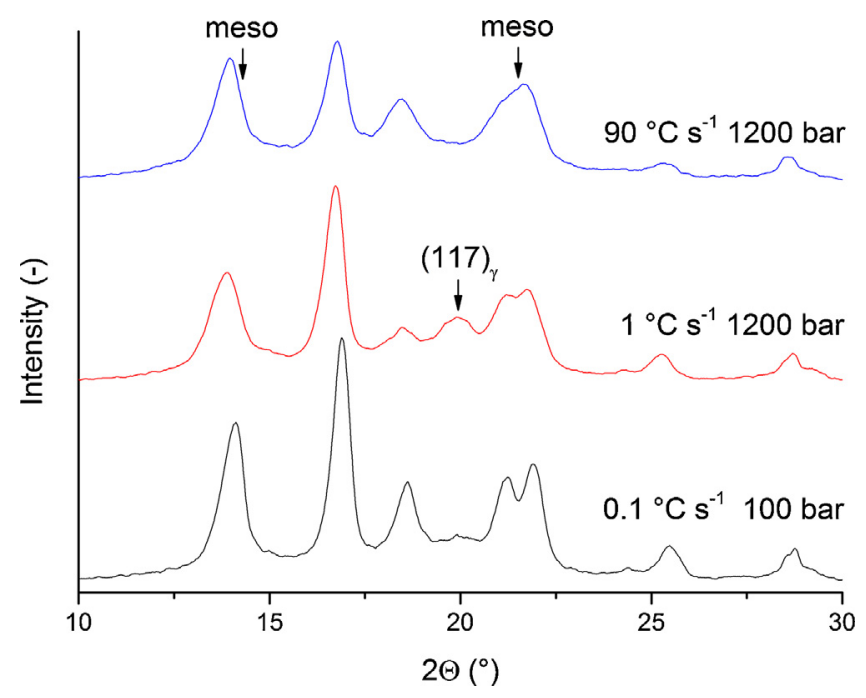

Fig. 4. WAXD diffractograms of PP-2 under different cooling conditions. All diffractograms show the characteristic $\alpha$-crystal phase reflections, while in some diffractograms reflections of the $\gamma$-crystal phase and the mesomorphic phase of $i$-PP are observed.

\subsection{Isothermal fast cooling of nucleated and non-nucleated i-PP}

Differential fast scanning calorimetry experiments were done isothermally to simulate injection or compression molding cooling conditions near the mold wall. In Fig. $3 \mathrm{~B}$ and C, the heat flow curves of isothermally crystallized PP-1 and PP-2 are displayed, respectively. Here, the shift in peak position as a function of isothermal crystallization temperature is clearly observed. In Fig. $3 \mathrm{~A}$, the crystallization half time $t_{1 / 2}$, which is an expression of the overall crystallization rate, is plotted as a function of crystallization temperature. From Fig. 3A, it is observed that virgin $i$-PP shows the characteristic double bell-shaped curve [51]. The observed kink at $40^{\circ} \mathrm{C}$ is attributed to a change from the $\alpha$-crystal phase at higher crystallization temperatures to a combination of the $\alpha$-crystal and mesomorphic structure at lower isothermal crystallization temperatures. The nucleated $i$-PP (PP-2) shows a similar trend, but the crystallization half time is somewhat lower at isothermal crystallization temperatures $>40^{\circ} \mathrm{C}$, which is due to the presence of the nucleating agent. One should be cautious to interprete results for recycled materials. In non-isothermal experiments it was observed that crystallization of $\mathrm{PE}$, and thereby crystallization of $i$-PP $[49,50]$, cannot be suppressed, not even at high cooling rates. At these cooling rates, the onset of PE crystallization starts at about $80^{\circ} \mathrm{C}$. Therefore, the crystallization process for isothermal crystallization temperatures below $80^{\circ} \mathrm{C}$ already starts during the cooling step from the melt. The observed 
Table 2

Structural and mechanical properties of nucleated and non-nucleated $i$-PP under different cooling conditions.

\begin{tabular}{|c|c|c|c|c|c|c|c|}
\hline Material & $\begin{array}{l}\text { Crystallization } \\
\text { conditions }\end{array}$ & $i$-PP crystallinity (\%) & $\begin{array}{l}\text { Crystalline } \gamma \text {-/meso-fraction } \\
(-)\end{array}$ & Young's modulus (MPa) & Yield stress (MPa) & Strain at break (\%) & $\lambda_{n}(-)$ \\
\hline \multirow[t]{3}{*}{ PP-1 } & $0.1^{\circ} \mathrm{Cs}^{-1} 100$ bar & 41 & & $819 \pm 105$ & $30.3 \pm 2.4$ & $556 \pm 64$ & 4.0 \\
\hline & $1^{\circ} \mathrm{Cs}^{-1} 1200 \mathrm{bar}$ & 36 & $0.60(\gamma)$ & $803 \pm 34$ & $28.7 \pm 1.4$ & $608 \pm 27$ & 3.9 \\
\hline & $90^{\circ} \mathrm{Cs}^{-1} 1200 \mathrm{bar}$ & n.d. & $0.53(\mathrm{~m})$ & $546 \pm 44$ & $17.7 \pm 1.1$ & $991 \pm 85$ & 3.2 \\
\hline \multirow[t]{3}{*}{ PP-2 } & $0.1^{\circ} \mathrm{Cs}^{-1} 100 \mathrm{bar}$ & 47 & & $798 \pm 63$ & - & $7 \pm 1$ & p.y. \\
\hline & $1^{\circ} \mathrm{Cs}^{-1} 1200 \mathrm{bar}$ & 39 & $0.69(\gamma)$ & $701 \pm 155$ & $30.8 \pm 0.7$ & $595 \pm 321$ & 4.4 \\
\hline & $90^{\circ} \mathrm{Cs}^{-1} 1200 \mathrm{bar}$ & n.d. & $0.18(\mathrm{~m})$ & $692 \pm 41$ & $25.6 \pm 1.3$ & $877 \pm 195$ & 4.2 \\
\hline \multirow[t]{3}{*}{ PIPP } & $0.1^{\circ} \mathrm{Cs}^{-1} 100 \mathrm{bar}$ & 36 & & $601 \pm 20$ & - & $12 \pm 4$ & p.y. \\
\hline & $1^{\circ} \mathrm{Cs}^{-1} 1200 \mathrm{bar}$ & 30 & $0.71(\gamma)$ & $560 \pm 14$ & $21.1 \pm 0.1$ & $29 \pm 14$ & p.y. \\
\hline & $90^{\circ} \mathrm{Cs}^{-1} 1200 \mathrm{bar}$ & n.d. & $0.17(\mathrm{~m})$ & $487 \pm 26$ & $18.6 \pm 0.5$ & $346 \pm 126$ & 3.6 \\
\hline \multirow[t]{3}{*}{ РСРP } & $0.1^{\circ} \mathrm{Cs}^{-1} 100$ bar & 30 & & $559 \pm 39$ & - & $20 \pm 4$ & p.y. \\
\hline & $1^{\circ} \mathrm{Cs}^{-1} 1200 \mathrm{bar}$ & 25 & $0.75(\gamma)$ & $500 \pm 22$ & $21.0 \pm 0.3$ & $73 \pm 51$ & p.y. \\
\hline & $90^{\circ} \mathrm{Cs}^{-1} 1200 \mathrm{bar}$ & n.d. & $0.22(\mathrm{~m})$ & $449 \pm 26$ & $18.0 \pm 0.5$ & $635 \pm 411$ & 3.7 \\
\hline
\end{tabular}

n.d.: not determined, p.y.: pre-yield failure.

crystallization peak at these temperatures cannot clearly be assigned to either PE or $i$-PP. The resulting crystallization half times should therefore be considered with great care. At isothermal crystallization temperatures higher than $80^{\circ} \mathrm{C}$, both PIPP and PCPP show a reduced $t_{1 / 2}$ compared to PP-1, indicating a higher number of nuclei in recycled materials.

\subsection{Structural analysis}

Differential fast scanning calorimetry was done on very small sample masses and under ambient pressure only. In order to measure some more representative quantities under higher pressures, dilatometry was used. The compression molding process was simulated by applying no active cooling and low pressures $\left(0.1^{\circ} \mathrm{C} \mathrm{s}^{-1}, 100 \mathrm{bar}\right)$, resulting in $\alpha$-crystal phase formation. Moderate cooling rates and high pressures are known to result in a prevailing $\gamma$-crystal phase formation of $i$-PP $\left(1^{\circ} \mathrm{Cs}^{-1}\right.$, $1200 \mathrm{bar})$, while rapid water cooling and high pressure $\left(90^{\circ} \mathrm{C} \mathrm{s}^{-1}\right.$, 1200 bar) promote the formation of the mesomorphic phase. It has to be noted that at these cooling rates the mesomorphic shoulder as presented in Fig. 1 is not yet observable. The diffractograms for PP-2 under different cooling conditions are shown in Fig. 4. The other materials showed similar diffractograms. It was confirmed that the cooling conditions applied in the dilatometer result in the desired crystal phase formations, despite limitations in the maximum attainable cooling rate. The amount of each crystal phase was analyzed by peak deconvolution of the WAXD patterns (Table 2). The amount of $\gamma$-crystal phase formed varied from $60 \%$ in PP-1 to 75\% in PCPP. In agreement with literature, the presence of nucleating agents promotes $\gamma$-crystal phase formation [52]. On applying higher cooling rates, the mesomorphic phase $i$-PP is formed in quantities ranging from 17\% for PIPP to 53\% for PP-1. In agreement with literature, a higher molecular weight results in more mesomorphic phase formation [41].

The crystallinity of a polymer is expected to be higher at lower cooling rates. Due to the reeling-in process a better crystal perfection is obtained. In Table 2, it is seen that for all samples crystallized at a constant pressure of 100 bar the crystallinity at lower cooling rates is a few percent higher. Since the mesomorphic phase rearranges to the $\alpha$-crystal phase upon heating, the crystallinity of the samples cooled down at $90{ }^{\circ} \mathrm{C} \mathrm{s}^{-1}$ could not be determined. For similar cooling rates, the crystallinity decreases with increasing pressure.

\subsection{Mechanical properties}

In this section, the effect of cooling conditions on the mechanical properties of $i$-PP is discussed. Especially for recycled $\mathrm{PP}$, it is interesting to see if changing these parameters can lead to desired ductility. The mechanical properties of the compressionmolded plaques and dilatometer rings were measured by tensile
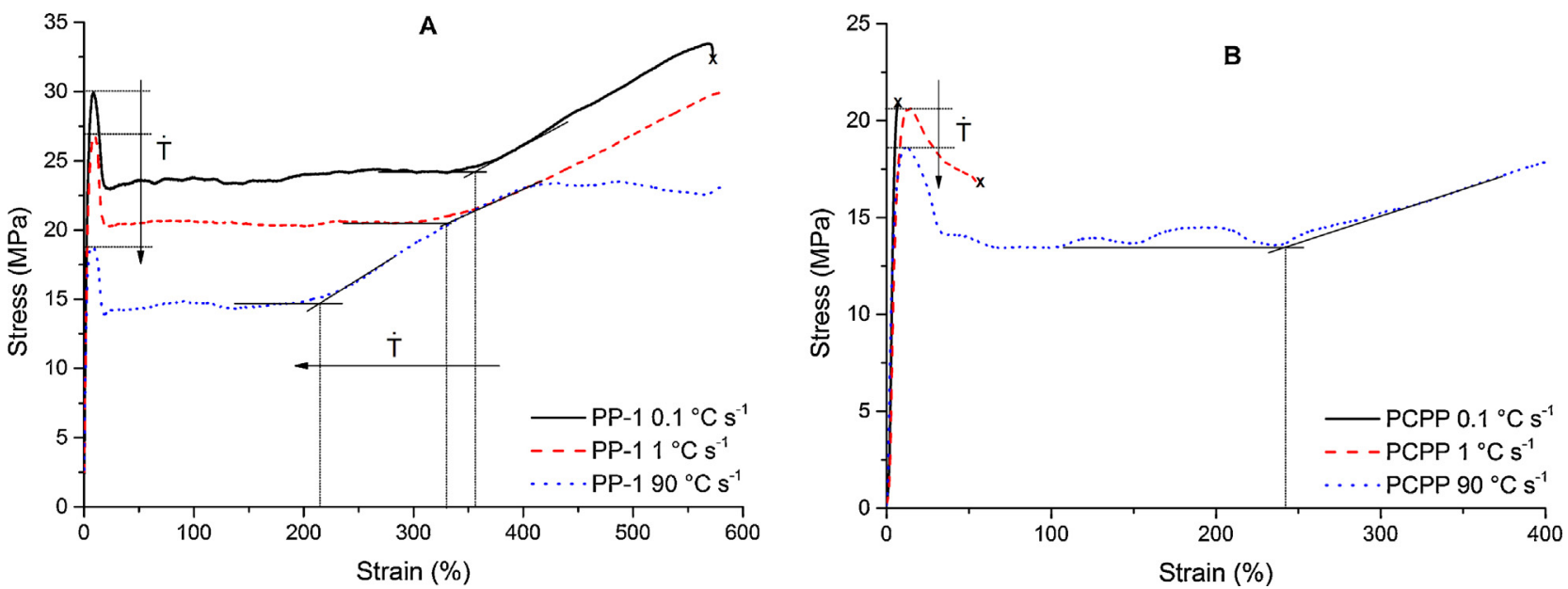

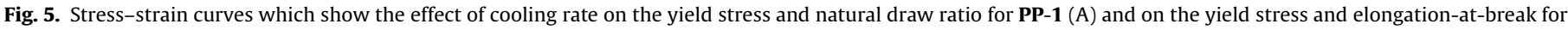
PCPP (B). 

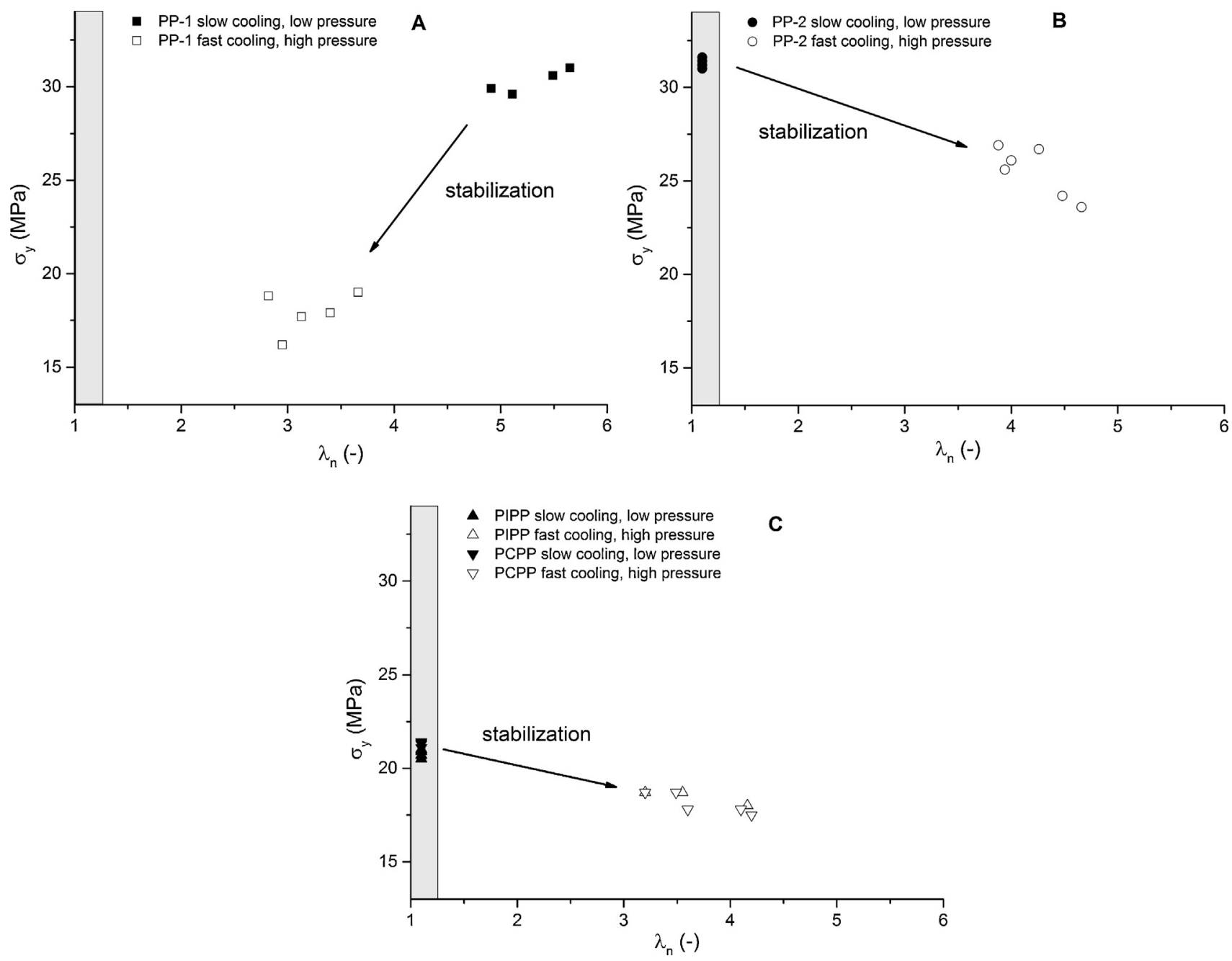

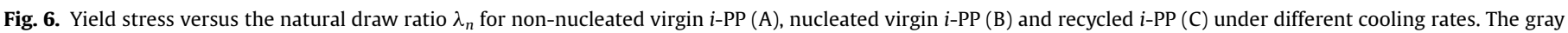
areas indicate pre-yield failure.

testing. An overview of the results of the dilatometer rings is given in Table 2 and Fig. 5. The modulus is mainly governed by the crystallinity, while the yield stress depends on the crystallization conditions. The natural draw ratio, $\lambda_{n}$, is dependent on both the yield stress and the crystallization conditions.

For all materials, similar trends are observed for similar cooling conditions. It is seen that the modulus of the $\gamma$-crystal phase and the mesomorphic phase materials is lower than for the $\alpha$-crystal phase material, which was also observed in other studies [30]. The reason for this is the reduced crystallinity. In agreement with literature, the yield stress decreases with increasing cooling rate at constant pressure [29]. As a result of this, the natural draw ratio decreases (see Fig. 5A). A lower value of $\lambda_{n}$ corresponds to a reduced stress localization in the neck, which improves the stability during deformation. As a result, the elongation-at-break increases. The highest elongation-at-break values are obtained for materials with a reduced modulus and yield stress. Recycled materials can fail either because of initiation effects (impurities) or instabilities during neck propagation. A critical process for PIPP and PCPP during deformation is the formation of a neck after yielding. Impurities which act as stress concentrators can cause fracture when the neck propagates through the tensile specimen, before the material can display strain hardening. Compared to virgin $i$-PP, the yield stress of recycled $i$-PP is low, which is a result of the presence of $P E$, which affects the crystallinity.
The cooling conditions have a significant influence on the entanglement density in the amorphous phase [27]. In tensile testing, the differences are best shown when plotting the yield stress as a function of the natural draw ratio $\lambda_{n}$, i.e., the elongation between the end of the neck formation and the onset of the strain hardening regime. The results are given in Fig. 6 . The gray areas indicate pre-yield failure.

Fig. 6 shows two distinct trends, i.e., one related to nonnucleated $i$-PP (Fig. 6A) and one to nucleated $i$-PP (Fig. 6B and C). Slowly cooled non-nucleated PP-1 has a high yield stress and natural draw ratio. A high natural draw ratio indicates a large stress concentration acting on a very small cross-sectional area, which can give rise to stability problems at larger deformations. Increasing the cooling rate lowers both the yield stress and the natural draw ratio, which improves the stability of the material during deformation in tensile testing, as observed by an increased elongation-at-break. In Fig. 6A this trend is indicated by an arrow. Nucleated $i$-PP which is cooled down slowly from the melt is highly unstable due to pre-yield failure or unstable neck propagation. Here, failure is governed by initiation effects. Strain hardening behavior was never observed for all slowly cooled nucleated samples. When these materials are quenched from the melt, i.e., high cool rates are involved, the yield stress decreases. This behavior is in agreement with the behavior observed for nonnucleated $i$-PP. In analogy to these materials, the nucleated $i$-PP materials shift from an unstable regime to a more stable regime, 
again indicated by the arrow. Remarkably, both nucleated and nonnucleated $i$-PP samples show similar values for yield stress and natural draw ratio upon fast cooling and a distinction between these materials can no longer be made.

\section{Conclusions}

In this research, the effect of cooling rate and pressure on the structure-property relationships was studied for non-nucleated and nucleated $i$-PP by means of differential fast scanning calorimetry, dilatometry, WAXD and tensile testing. Conclusions are made for non-nucleated, nucleated, and recycled $i$-PP.

\subsection{Non-nucleated virgin i-PP}

From the non-isothermal fast scanning calorimetry experiments, it was seen that upon higher cooling rates, more mesomorphic phase was formed, which was confirmed by the WAXD analysis. The crystallization temperatures of both phases decrease with increasing cooling rate. Isothermal fast scanning calorimetry experiments showed the existence of the mesomorphic phase at high undercooling temperatures, which results in a reduction in crystallization half time. The dilatometry experiments showed that by applying pressure the $\gamma$-crystal and mesomorphic phase can be formed at macroscopic scale under different cooling rates. The mechanical tests on these samples showed that upon fast cooling the yield stress and the natural draw ratio of $i$-PP decrease. These effects result in an improved elongation-at-break and stability during uniaxial deformation.

\subsection{Nucleated virgin i-PP}

Compared to the conclusions drawn above, some differences in the behavior upon fast cooling are observed for nucleated virgin $i$ PP. In non-isothermal fast scanning calorimetry, the crystallization temperature of the mesomorphic phase was not clearly observable and appeared as a broad peak merging with the crystallization peak of the $\alpha$-crystal phase. Furthermore, the critical cooling rate of nucleated $i$-PP to obtain a fully amorphous polymer is higher. In isothermal fast scanning calorimetry experiments, it was observed that the crystallization half time of the $\alpha$-crystal phase was reduced, while the crystallization of the mesomorphic phase occurred at the time scales observed for the non-nucleated systems. From the dilatometry experiments and WAXD analysis, it was seen that the $\gamma$-crystal phase formation is favored in nucleated $i$-PP, while the mesomorphic phase formation is suppressed. Slowly cooled nucleated $i$-PP showed brittle failure, but by increasing the cooling rate, the yield stress can be reduced and the natural draw ratio can be increased, which improves the stability of the material upon uniaxial deformation.

\subsection{Recycled i-PP}

Recycled $i$-PP behaves similar to nucleated virgin $i$-PP, which is explained by the presence of PE that has a nucleating effect on $i$-PP. However, some differences are observed. In non-isothermal fast scanning calorimetry, the increase in mesomorphic phase crystallization temperature is not as high as for virgin nucleated $i$-PP, but more prominent than for non-nucleated virgin $i$-PP. The crystallization of PE contaminant was observed for all cooling rates and could not be suppressed. From the dilatometry experiments and WAXD analysis, it was observed that the $\gamma$-crystal phase formation is even more favored than in nucleated virgin $i$-PP. From the uniaxial mechanical tests, it can also be concluded that upon fast cooling the deformation process of the otherwise brittle material is stabilized which significantly improves the ductility.
This study showed that the cooling rate and pressure can be used to tailor the yield stress in combination with the post-yield deformation behavior and concomitantly the brittle-to-ductile transition for nucleated $i$-PP, independent of the origin of the material, either virgin or recycled.

\section{Acknowledgement}

This research was financially supported by the Top Institute for Food and Nutrition, Wageningen, the Netherlands (Project SD-001).

\section{References}

[1] U. Arena, M.L. Mastellone, F. Perugini, Int. J. LCA 8 (2003) 92-98.

[2] B.J. Luijsterburg, J.G.P. Goossens, Res. Cons. Rec. 85 (2014) 88-97.

[3] M. Hamskog, M. Klügel, D. Forsström, B. Terselius, P. Gijsman, Polym. Degrad. Stab. 86 (2004) 557-566.

[4] B. Lotz,S. Graff,J.C. Wittmann, J. Polym. Sci. Polym. Phys. Ed. 24(1986)2017-2032.

[5] B. Lotz, S. Graff, C. Straupe, J.C. Wittmann, Polymer 32 (1991) 2902-2910.

[6] B. Luijsterburg, P. Jobse, D. Hermida Merino, T. Peijs, H. Goossens, J. Polym. Sci. Pol. Phys. 52 (2014) 1071-1082.

[7] A.P. Moore, Polypropylene Handbook, Hanser Publishers, Munich, 1996.

[8] J. Varga, J. Macromol. Sci. B Phys. 41 (2002) 1121-1171.

[9] F.J. Padden, H.D. Keith, J. Appl. Phys. 30 (1959) 1479-1484.

[10] T. Labour, C. Gauthier, R. Séguéla, G. Vigier, Y. Bomal, G. Orange, Polymer 42 (2001) 7127-7135.

[11] J. Karger-Kocsis, J. Varga, J. Appl. Polym. Sci. 62 (1996) 291-300.

[12] J.X. Li, W.L. Cheung, Polymer 39 (1998) 6935-6940.

[13] W. Xu, D.C. Martin, E.M. Arruda, Polymer 46 (2005) 455-470.

[14] E.J. Addink, J. Beintema, Polymer 2 (1961) 185-193.

[15] J.L. Kardos, A.W. Christiansen, E. Baer, J. Polym. Sci. A-2 4 (1966) 777-788.

[16] B.A. Newman, S. Song, J. Polym. Sci. 9 (1971) 181-186.

[17] D. Cavallo, L. Gardella, G.C. Alfonso, D. Mileva, R. Androsch, Polymer 53 (2012) 4429-4437.

[18] G. Natta, M. Peraldo, P. Corradini, Rend. Accad. Naz. Lincei 24 (1959) 14-17.

[19] S. Piccarolo, J. Macromol. Sci. B 31 (1992) 501-511.

[20] M. van Drongelen, T.B. van Erp, G.W.M. Peters, Polymer 53 (2012) 4758-4769.

[21] R.L. Miller, Polymer 1 (1960) 135-143.

[22] G. Farrow, J. Appl. Polym. Sci. 9 (1965) 1227-1232.

[23] B. Wunderlich, J. Grebowicz, Adv. Polymer Sci. 60-61 (1984) 1-59.

[24] P.J. Hendra, J.Vile, H.A. Willis, V.Zichy, M.E.A. Cudby, Polymer 85 (1984) 785-790

[25] R. Saraf, R.S. Porter, Mol. Cryst. Liq. Cryst. Lett. 2 (1985) 85-93.

[26] P. Corradini, V. Petraccone, C. de Rosa, G. Guerra, Macromolecules 19 (1986) 2699-2703.

[27] B.A.G. Schrauwen, R.P.M. Janssen, L.E. Govaert, H.E.H. Meijer, Macromolecules 37 (2004) 6069-6078.

[28] T.B. van Erp, D. Cavallo, G.W.M. Peters, L.E. Govaert, J. Polym. Sci. Polym. Phys. 50 (2012) 1438-1451.

[29] Q. Zia, H.J. Radusch, R. Androsch, Polym. Bull. 63 (2009) 755-771.

[30] C. De Rosa, F. Auriemma, Angew Chem. Int. Ed. 51 (2012) 1207-1211.

[31] C. De Rosa, F. Auriemma, R. Di Girolamo, O. Ruiz de Ballesteros, J. Polym. Sci. Polym. Phys. 52 (2014) 677-699.

[32] C. De Rosa, F. Auriemma, R. Di Girolamo, O. Ruiz de Ballesteros, M. Pepe, O. Tarallo, A. Malafronte, Macromolecules 46 (2013) 5202-5214.

[33] C. De Rosa, F. Auriemma, O. Ruiz de Ballesteros, R. Di Girolamo, O. Tarallo, N Galotto Galotto, Macromol. Chem. Phys. 214 (2013) 1951-1964.

[34] R.N. Haward, Polymer 28 (1987) 1485-1488.

[35] R.N. Haward, Polymer 35 (1994) 3858-3862.

[36] H.G.H. van Melick, L.E. Govaert, H.E.H. Meijer, Polymer 44 (2003) 3579-3591.

[37] H.E.H. Meijer, L.E. Govaert, Prog. Polym. Sci. 30 (2005) 915-938.

[38] F. de Santis, S. Adamovsky, G. Titomanlio, C. Schick, Macromolecules 39 (2006) 2562-2567.

[39] D. Mileva, R. Androsch, E. Zhuravlev, C. Schick, B. Wunderlich, Thermochim. Acta 522 (2011) 100-109.

[40] A. Martorana, S. Piccarolo, F. Scichilone, Macromol. Chem. Phys. 198 (1997) 597-604.

[41] A.M.J.T. Meijer-Vissers, J.G.P. Goossens, Macromol. Symp. 330 (2013) 150-165.

[42] V. La Carrubba, S. Piccarolo, V. Brucato, J. Appl. Polym. Sci. 104 (2007) 1358-1367.

[43] D. Cavallo, Polymer Structuring Under Processing-Relevant Conditions Ph.D. Thesis, University of Genoa, Genoa, Italy, 2011.

[44] van der Beek, G.W.M. Peters, H.E.H. Meijer, Int. Polym. Proc. 20 (2005) 111-120

[45] R. Forstner, G.W.M. Peters, H.E.H. Meijer, Int. Polym. Proc. 24 (2009) 114-121.

[46] R. Forstner, G.W.M. Peters, C. Rendina, J.W. Housmans, H.E.H. Meijer, J. Therm. Anal. Calorim. 98 (2009) 683-691.

[47] www.imetechnologies.nl.

[48] G. Lamberti, Polym. Bull. 52 (2004) 443-449.

[49] A.J. Lovinger, M.L. Williams, J. Appl. Polym. Sci. 25 (1980) 1703-1713.

[50] J.C. Wittman, B. Lotz, Polymer 30 (1989) 27-34.

[51] F. de Santis, S. Adamovsky, G. Titomanlio, C. Schick, Macromolecules 40 (2007) 9026-9031.

[52] T. Foresta, S. Piccarolo, G. Goldbeck-Wood, Polymer 42 (2001) 1167-1176. 